\title{
6
}

\section{COULD WE/SHOULD WE ERADICATE MOSQUITOES?}

\section{The case of the yellow fever vector ${ }^{1}$}

\author{
Nancy Leys Stepan
}

It is impossible to write about controlling infectious diseases without having the pandemic of coronavirus in the forefront of our minds. COVID-19 has brought home to all of us very forcefully indeed the incompleteness of our scientific knowledge in the face of novel pathogens, the lack of government preparedness despite repeated forewarnings, and the often fumbling and inconsistent nature of public policies when we are faced with mass public health threats.

Zika provides another example of an uncertain response to an epidemic less universal in scope than coronavirus, but deeply worrying. In 2015 world health experts began to hear about an eruption of an apparently novel viral infection in northeastern Brazil. Zika was not in fact unknown to scientists; but its association in the Brazilian outbreak with microcephaly in newborn infants was unexpected and shocking, and led the World Health Organization (WHO) in early 2016 to declare a Public Health Emergency of International Concern (PHEIC) (Lowe et al., 2018). Zika eventually spread to over 80 countries (Chippaux and Chippaux, 2018). Almost overlooked at the time, but also very troubling, was an outbreak of yellow fever in the states of Rio de Janeiro and São Paulo later that same year-one of the largest such outbreaks in Latin America in decades. And let's not forget the epidemics of chikungunya and especially dengue fever that have plagued the country in recent years (Gubler, 2004).

What distinguishes these viral diseases from COVID-19 is that they involve, either directly or potentially, an insect vector or transmitter, the Aedes aegypti mosquito, an age-old "enemy" of public health. In response to Zika, the President of Brazil, Dilma Rouseff, hastily targeted the mosquito, sending in 220,000 soldiers to help with insecticiding, while acknowledging that Brazil was already losing the battle against the insect. This was the country that had once almost eradicated this mosquito. So what had happened? Why had vector eradication been given up? Could we do it again? Should we? 
After all, most of the more than 3,500 species of mosquito recognized by scientists so far do not transmit diseases to humans. Some species do not bite humans at all, and others are merely a nuisance, with many of them remaining very useful to local ecologies, as pollinators or as food for other animals. So we should learn to live with them.

It's the exceptions that we worry about. Ever since Ross and Grassi proved in 1897-1898 that anopheline mosquitoes transmit malaria, and the Reed Commission established in 1900 that the Aedes aegypti mosquito transmits yellow fever, getting rid of these mosquito vectors has been taken to be a legitimate, even necessary, method of disease control. All thought of ecological balance or cooperative living with insects seems to fly out the window once we are in the midst of a mosquito-transmitted epidemic.

It is these dangerous mosquitoes that form the crux of the question asked in this book: "If we could rid ourselves of mosquitoes, would we still want to?" This question does an excellent job of focusing attention on critical matters of ecology and ethics in relation to mosquitoes. But as a medical historian who has engaged with the messy details of past efforts to control mosquitoes, I find it difficult to abstract the "could we?" part of the story from the "should we?". Difficult, that is, to disentangle or bracket off eradication or the "getting rid of" process, because embedded in the "could we?" are already many issues of "should we?". How is extermination (or severe reduction) of a mosquito species to be carried out, and at what cost? What eradication methods do we propose? Are there ecological and/or ethical issues associated with these methods? What does "eradication" of a mosquito species imply: local elimination, or worldwide reduction to zero? Is it possible to eradicate an entire mosquito species?

For answers to such questions I turn to what is possibly the best piece of historical evidence available, the extensive pre- and post-World War II campaign to definitively eradicate the Aedes aegypti mosquito from the entire continental Americas. I evaluate why, given the existence of an excellent vaccine against yellow fever, the eradication of a mosquito species was chosen as the main method of urban yellow fever control in the Americas, and why the French colonial authorities in West Africa focused largely on mass vaccination instead.

I end the chapter by bringing the issue of mosquito eradication/control back to our ongoing worries about the return and spread of the Aedes aegypti mosquito in the Americas, Africa and Asia, keeping in mind the epidemiologically difficult conditions of contemporary urban life. As noted already, Aedes aegypti is implicated in the transmission of dengue and chikungunya, as well as yellow fever and Zika. Other Aedes species, such as $A$. albopictus, are also capable of acting as vectors for these diseases. Is mass vaccination the path to follow, assuming a vaccine is even available? Or is vector control still a necessary part of disease control? What about social investments and infrastructural improvements?

I use the Aedes aegypti eradication campaign here as paradigmatic of a certain style or model of mosquito eradication and/or control. In concluding my 
chapter, I contrast that style with a potential alternative model, though in the end, I am only able to sketch the outlines of that model.

\section{The background: eradicating malaria mosquitoes}

The campaign to eradicate the Aedes aegypti mosquito was led by Dr. Fred L. Soper, first in his position as a Rockefeller Foundation (RF) officer in Brazil, where from 1930 until 1942 he directed the RF-Brazilian National Cooperative Yellow Fever Service, and second, in his capacity as Director from 1947 to 1959 of the Pan American Health Organization (PAHO), the American regional office of WHO.

As the arch-eradicationist of his day, Soper was associated with most of the eradication campaigns of the twentieth century, against yaws, smallpox, malaria and yellow fever. In the case of malaria and yellow fever, mosquito reduction was a well-established method of halting disease transmission. Soper's contribution was to try to shift the focus of eradication from the disease, to the vector mosquitoes themselves. Instead of mosquito reduction, Soper aimed for vector extirpation. A larger-than-life character, admirable in his tenacity, Soper was also dogmatic and often wrongheaded. A gift, in short, to medical historians.

A brieflook at three experiments with mosquito eradication focused on malaria vectors provide context to Soper's much longer effort to extirpate the urban yellow fever mosquito, Aedes aegypti. Malaria at the time was understood to have a very complex etiology, involving multiple factors-ecological, environmental and social, as well as vectorial. In the face of causal complexity, Soper offered instead blunt simplicity, with equivocal results.

First Soper tried to wipe out the highly "efficient" and anthropophilic malaria vector, Anopheles gambiae, from an area in the northeast of Brazil (1938-1941), and then again in Upper Egypt (1944-1945), both times in response to severe malaria epidemics. Concentrating his anti-malaria efforts exclusively on eliminating the gambiae, using the pre-DDT insecticide house spraying and anti-larval methods perfected for yellow fever, and ignoring all other causes of the epidemics (e.g. troop mobilization, population displacements or other malaria vectors), Soper attributed the end of these malaria epidemics entirely to the disappearance of the gambiae species in the two regions (Packard and Gadelha, 1997; Stepan, 2011).

At the time, a malaria expert hailed the vanquishing of the gambiae as "one of the greatest accomplishments in all malariology" (Stepan, 2011). Yet in truth, the results were ambiguous. The gambiae mosquito was a recent arrival in both Brazil and Egypt, and so not fully integrated into the local ecology. Soper's extermination efforts were noteworthy examples of stopping invasions of a dangerous species - and of potential relevance today, as mosquito species expand into new places as a result of climate change, human mobility and other factors-but not a true test of the possibility of eradicating an indigenous or well-established mosquito species over a large area, let alone the world. 
A third species eradication campaign (1946-1950), this time against Anopheles labranchiae on the very malarial island of Sardinia, was such a test, indeed a genuine experiment, organized by Soper, with the backing of the Rockefeller Foundation and the post-war Italian government, in a deliberate attempt to rid the island completely of an indigenous malaria-transmitting mosquito species. The campaign was based on the spraying of thousands of tons of the new wartime discovery, DDT, from the air and in homes. At the end of five years, malaria had disappeared, and did not reappear when spraying stopped-seemingly a very satisfactory public health result. But the mosquito itself survived, if only in severely reduced numbers. Considered a test of mosquito eradication, the Sardinian Project proved that completely eradicating a well-established mosquito was very difficult, even impossible, at least by spraying DDT over the kind of terrain where this mosquito was found. Turning this around, the best that could be said was that species eradication was apparently not essential to malaria eradication (Hall, 2010; Stepan, 2011).

From Soper's viewpoint, this was a hard lesson to learn, one reason no doubt why he barely acknowledged it as such. In fact, he continued to refer to the eradication of the main malaria vector in Sardinia as though it were a fait accompli, a rare lapse in a person given to accuracy. He chose to ignore the ambiguities of the results and continued to endorse the concept of species eradication, even though the concept was dropped from the most important post-war eradication effort, the WHO's Malaria Eradication Programme (MEP), where the aim was eradication of the disease, not its vectors. As happens so often in public health, Soper had devised his strategy while operating with incomplete knowledge-in these cases, incomplete knowledge of insect ecology.

\section{Eradicating Aedes aegypti: the rationale}

Soper's anti-Aedes aegypti campaign is the least remarked on of his four-vector extermination efforts, but perhaps the most interesting because it was by far the most sustained of its kind, and because it captures so well the ambition as well as the ambiguities of what was aimed for.

Paradoxically, Soper advocated Aedes aegypti eradication just when it was being realized that yellow fever is not the kind of disease that could, on biological grounds, be eradicated, the long-standing goal of the RF. Unexpected outbreaks of yellow fever in rural areas of Brazil had led to the belated realization by the mid1930s that an animal reservoir of the virus existed, the virus being transmitted in rural areas from forest animals, mainly monkeys, to humans by the bite of mosquitoes other than the urban Aedes aegypti, such as species of Haemogogus. Searching for yellow fever in the main cities and for a single vector, the RF had for years overlooked, or rejected the diagnosis of, yellow fever outbreaks in rural areas. The jungle (or sylvatic) cycle of yellow fever showed that it was wrong to rely on the exclusively urban identity of yellow fever, on which the RF had based its yellow fever eradication strategy. 
In rethinking yellow fever epidemiology, it was evident that yellow fever could not be eradicated short of killing off all forest animals harbouring the virus. The RF accordingly abandoned its goal of yellow fever eradication in the late 1930s, leaving as its legacy of decades of anti-yellow fever work, its new 17D yellow fever vaccine.

Soper saw the matter differently. As director of Brazil's national anti-yellow fever service, he had begun in the early 1930s to extend mosquito control to include small rural towns where yellow fever also circulated. Without aiming for it as such, he found that the methods he was using were resulting in the complete disappearance of Aedes aegypti. Inspections in town after town showed that the mosquito was gone. From the late 1930s on, as the RF abandoned eradicating the disease, Soper began to promote the idea that public health efforts should shift to complete mosquito eradication (Soper and Wilson, 1942; Soper, 1963) (See Figure. 6.1).

True, jungle yellow fever would remain a constant potential source of the virus, but this yellow fever cycle was sporadic and involved only populations working on the rural borderlands with forests where the animals lived. In the 1930s, Brazil was already an increasingly urbanized country, and it was in the cities that the greatest number of deaths from yellow fever occurred. Soper's public health contribution was to replace mosquito reduction with a new absolute: the complete elimination of a vector that was highly adapted to urban and human life. In this way, urban yellow fever itself would be eliminated.

The trouble, as Soper saw it, with aiming for mere Aedes aegypti control (that is, simply reduction of mosquitoes and their larvae to low numbers), as previous yellow fever campaigns had done, was that the authorities invariably relaxed

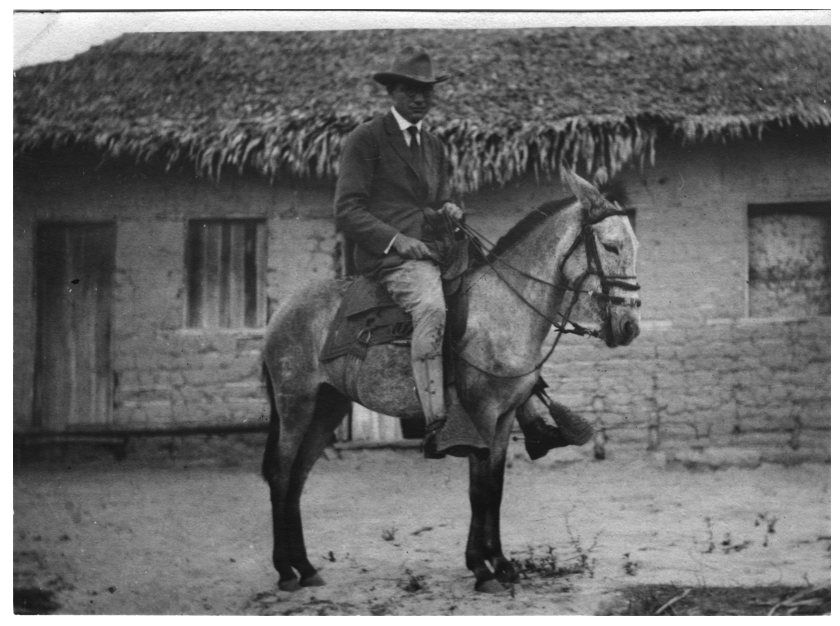

FIGURE 6.1 Fred Soper preparing for an inspection tour of Maranhao, Brazil; 1920s. Image courtesy of the National Library of Medicine. 
controls as the urban cases of the disease diminished. The outcome was the eventual return of yellow fever from its rural home to cities, often in explosive epidemics. Why, then, not eradicate the urban mosquito once and for all and stop these cycles?

Soper acknowledged that such an absolutist goal was hard to achieve; it required more money and effort upfront, and more determination. But once achieved, there were huge savings to be had in terms of safety and costs; all controls in urban areas could be given up; with the urban vector wiped off the face of the earth, it could never return to act as a vector again. Making urban areas safe in this way, control and surveillance would be focused eventually on rural areas where yellow fever was only sporadic. The majority of the population, located in cities and towns, would be free of yellow fever forever. To work, however, this new concept of eradication had to be absolute. Any chance that Aedes aeygpti mosquitoes might be reintroduced from the outside, into an urban area made free of them for years, would be potentially disastrous, as by this time the city would be filled with highly susceptible people who had never had yellow fever and so never acquired the immunity conferred by a mild childhood infection.

\section{Yellow fever and vaccination}

And what about vaccination, usually considered the magic tool of preventive medicine? The isolation of the yellow fever virus in 1927 had provided scientists with an animal model and had led to an intense search for a vaccine. In 1932 French researchers at the Pasteur Institute in Dakar, Senegal, produced a yellow fever vaccine based on one strain of the virus, and in 1937 the Americans, working at the RF laboratory in New York, and relying on the different "Asibi" strain of the virus, produced their own 17D vaccine, used to this day.

Almost immediately, the French launched mass vaccination campaigns in their West African colonies, despite their vaccine's comparatively high numbers of negative neurotropic side effects, notably encephalitis. The scratch method of application in smallpox was well established in Africa, and smallpox vaccination had been made compulsory in the French colonies early, so the yellow fever vaccine was administered by the scratch method, by itself or more often together with smallpox vaccine. The epidemiology of yellow fever was complex in Africa, involving different transmission cycles and several Aedes species in addition to $A$. aegypti, factors making mosquito control difficult to carry out beyond selected places like airports. Immunity surveys were still mapping the geography of yellow fever distribution; the population in Africa was still largely rural, and accustomed to mandatory vaccination for smallpox. In the circumstances, mass vaccination was a rational approach to yellow fever control.

Fear of yellow fever outbreaks among the troops mobilized for World War II led to some 14,300,000 people receiving the single yellow fever or the mixed yellow fever-smallpox vaccine, out of a total population of some 16 million in French West Africa (Peltier, 1947). Altogether 53 million people were vaccinated by the 
French colonial authorities between 1939 and 1953. In fact, the use of yellow fever vaccination led to the virtual disappearance of yellow fever in francophone West Africa for decades. Nothing like the French colonial vaccination effort was undertaken in British colonial West Africa, where numerous outbreaks of yellow fever occurred (Monath, 1991).

The RF vaccine differed from that of the French in requiring an injection rather than a scratch. The $17 \mathrm{D}$ vaccine was tested in Brazil, and by the end of 1938 over a million people in the country had been vaccinated. Initially, this vaccine also produced negative side effects, notably hepatitis, which was only eliminated when human serum, the source of contamination, was removed from the vaccine. Once this problem was solved, vaccination of people exposed to the rural cycle of yellow fever was resumed. Over time, the 17D vaccine would be considered safer than the French vaccine (the latter ceasing production in 1982), but the RF conceded at the time that the low-cost scratch immunization made better sense in large rural populations of French colonial West Africa (Durieux, 1956; Frierson, 2010; Strode, 1951).

As head of the RF-Brazilian yellow fever service, Soper was responsible for supervising the production, testing and distribution of the $17 \mathrm{D}$ vaccine in Brazil (Benchimol, 2001). But he had reservations about relying exclusively on the new vaccine; it was expensive to produce and required a cold chain for its distribution. $\mathrm{He}$ also worried that demand would outrun supplies. More than this, because yellow fever is often a silent, under-reported disease, Soper was alert to the fact that, unless rural vaccination rates were kept up, the virus could pass unnoticed via its initial rural path into urban areas which, if still infested with Aedes aegypti mosquitoes, could have outbreaks of yellow fever before vaccination could be hurriedly introduced to halt its spread. Once administered, a further interval of time (roughly ten days) had to pass before individuals acquired adequate immunity. For these reasons, Soper was always sceptical of controlling yellow fever solely by vaccination. In this respect, Soper may have been right-an issue taken up at the end of this chapter.

\section{Eradicating Aedes aegypti in practice}

So much for the rationale for Aedes aegypti eradication. Crucial to its execution-the "could we?" question-was the confidence Soper had in his methods. As originally established by William Gorgas in Havana in 1901, these involved a mix of the social, biological and chemical, packaged into a top-down, singledisease, military-style campaign: the isolation of those infected, removal of water receptacles near human habitations, and destruction of mosquitoes by chemicals such as crude oil mixed with paraffin and floated on water as a larvicide. Gutters were cleared. Gambusia fish were sometimes introduced to water tanks to eat larvae. Beginning in the 1920s, the arsenic-based chemical, Paris Green, was used in place of oil, in a process called "Greening" by RF personnel. Pyrethrum insecticides were sprayed inside houses 
These chemicals had nothing like the potency of DDT, so success with mosquito reduction or actual elimination depended on systematic attention to public health administration: to the routinization of house visits, meticulous larviciding, tight supervision of the "mosquito brigades" of inspectors looking for mosquito infestations, and rigid controls of householders, making sure they kept water receptacles empty or covered to prevent Aedes aegypti breeding in them.

This is where Soper excelled, his methods being described as "perfectionism at the end of the line." To the established anti-mosquito techniques, Soper added new ones to make otherwise invisible mosquitoes visible, such as the use of "mother squads" of mosquito inspectors to hunt down hidden breeding female mosquitoes in houses, the carrying out of immunity surveys to identify otherwise unsuspected locations of yellow fever, and the creation of a "viscerotomy" service to conduct post-mortem analyses to detect overlooked yellow fever deaths (Löwy, 1997; Stepan, 2011). Backed by Brazil's authoritarian president, Soper had the tools and resources to pursue Aedes aegypti eradication across the country.

The fundamental shift towards the "chemicalization" of anti-mosquito work came with the World War II discovery of the insecticidal properties of DDT. Released for civilian use at the end of the war, DDT was cheap, available, apparently safe, and much more powerful in its residual effects as a larvicide and adulticide than anything before it. It proved irresistible. Having participated in the first uses of DDT against typhus and malaria in Italy during his wartime service, Soper was quick to realize how its superior, long-lasting insecticidal properties would be crucial in his mosquito-killing projects.

\section{Eradicating Aedes aegypti: the impossible task}

When Soper had begun in the late 1930s to talk about exterminating the Aedes aegypti from all of Brazil, "yellow fever experts from Rio to New York laughed at him. They declined to be Soperized" (Stepan, 2011). But to Soper, getting rid of the mosquito was everything. Being elected Director of the Pan American Health Organization (PAHO) in 1947 gave him a wider stage for his eradicationist philosophy, Soper managing to persuade all the member countries of PAHO to embrace the eradication programme against $A$. aegypti throughout the continental Americas-even though there had been just one outbreak of urban yellow fever in the Americas in the preceding 15 years, and even if it meant ignoring the negative outcome of the Sardinia experiment.

And at first all went well. In 1958, Brazil became the first country in the Americas to be declared Aedes aegypti-free. Soon, country after country was being certified as Aedes aegypti-free too. By 1964, the vector had been successfully eradicated in most of South and Central America. Yellow fever disappeared. Thought of as a control effort, this was an impressive result. But thought of as a mosquito eradication campaign, not so. 
It turned out that only "most" countries were Aedes aegypti-free-there was the rub. Absolute success proved elusive, as continent-wide elimination of the mosquito was not maintained for very long, with constant reinvasion of mosquitoes into areas previously certified as clear. In 1976, the PAHO countries were still at their eradication project, but by this point with only ten countries certified as entirely free of the Aedes mosquito. Brazil, the largest endemic center of yellow fever in the Americas, had lost its Aedes aegypti-free status.

In regard to these failures, Soper blamed the USA for not doing its part and allowing its Aedes aegypti mosquitoes to invade Mexico. The USA had in fact always been reluctant participants in the project. The USA refused to take much action throughout the 1950s, despite having signed on to do so in 1947. The country had not suffered an indigenous case of yellow fever for 40 years, had no jungle reservoirs of the virus, and preferred to rely on the excellent yellow fever vaccine. Only in 1963 did the USA agree to get involved, less because of conviction about feasibility than as a political "goodwill" gesture. Terminating the project in 1968, the USA thought Aedes aegypti eradication was unnecessary and anyway unachievable (Sencer, 1969).

The USA's half-hearted participation and then withdrawal from the mosquito eradication project came just as public attitudes towards synthetic organic insecticides were changing. Rachel Carson's target in Silent Spring (1962) was DDT's overuse in agriculture; only one chapter in her trenchant book addressed synthetic insecticides in public health. Her main point there was to warn that excessive use of pesticides was creating insect resistance, leading public health officials to seek out new and yet more powerful insecticides, which resulted in yet more insect species acquiring resistance ... in a never-ending escalation.

Those involved in anti-malaria and yellow fever campaigns knew this to be true. Yet DDT continued to be used in public health (the USA banned it for agricultural use in 1972). After all, in the many WHO-connected expert reports on insecticides and safety, the conclusion was almost invariably drawn that the benefits of using DDT for public health purposes far outweighed its risks, despite mosquito resistance. Public health use of the new insecticides was, as it were, bracketed or protected as a special case.

But slowly, support for the Aedes eradication project was disappearing. One factor was simply programme fatigue, with countries tiring of directing so much effort against $A$. aegypti when mosquito and yellow fever indices were already so low as to be virtually non-existent-yet absolute eradication proved so elusive. The strategy of species eradication was not based on a medical emergency or an overwhelming medical problem but was, as Soper said, a deliberate effort to consolidate the gains of previous decades, and guarantee future freedom from yellow fever to the cities and towns of the Americas. It was a difficult case to make: if control methods had done such a good job, why aim for something so difficult as exterminating every last mosquito? "When could eradication be said to be complete and final," asked a French delegate at a PAHO meeting in 1970, "considering that a few mosquitoes were enough to cause re-infestation?" 
(Stepan, 2011). It was proving hard, if not impossible, to prevent constant reinfestation of already certified countries from across their borders. Simultaneous extermination of Aedes aegypti across the Americas seemed a Sisyphean task.

And yet, old dreams die hard. Soper retired from PAHO in 1959, but the organization carried on its species eradication mission well into the 1970s. But by 1985 it was time to give up, with PAHO finally admitting that the goal of Aedes aegypti eradication was unrealistic, and shifting its aims to keeping mosquito indices low. By the late 1990s, even routine control measures were being cut back in Brazil and elsewhere in the name of cost-saving, with the unsurprising outcome that $A$. aegypti returned everywhere, to then unleash epidemics of dengue, and now Zika. Soper's $A$. aegypti campaign had shown that mosquitoes are among the most resilient of animals; they resist their extermination (see Figure. 6.2).

\section{Could we/should we, ecologically/ethically?}

Turning now to some of the ecological and ethical issues tied up in the "could we/should we" nexus, Soper's eradication efforts were decidedly "pre-" and even "anti-" ecological. He famously declared that he regretted the term "ecology" had ever been invented. He knew very little about Anopheles gambiae or $A$. labranchiae when he set out to eradicate them in northeastern Brazil, Upper Egypt and Sardinia, treating them as though they were the same, in relation to eradication methods, as the very different Aedes aegypti mosquito.

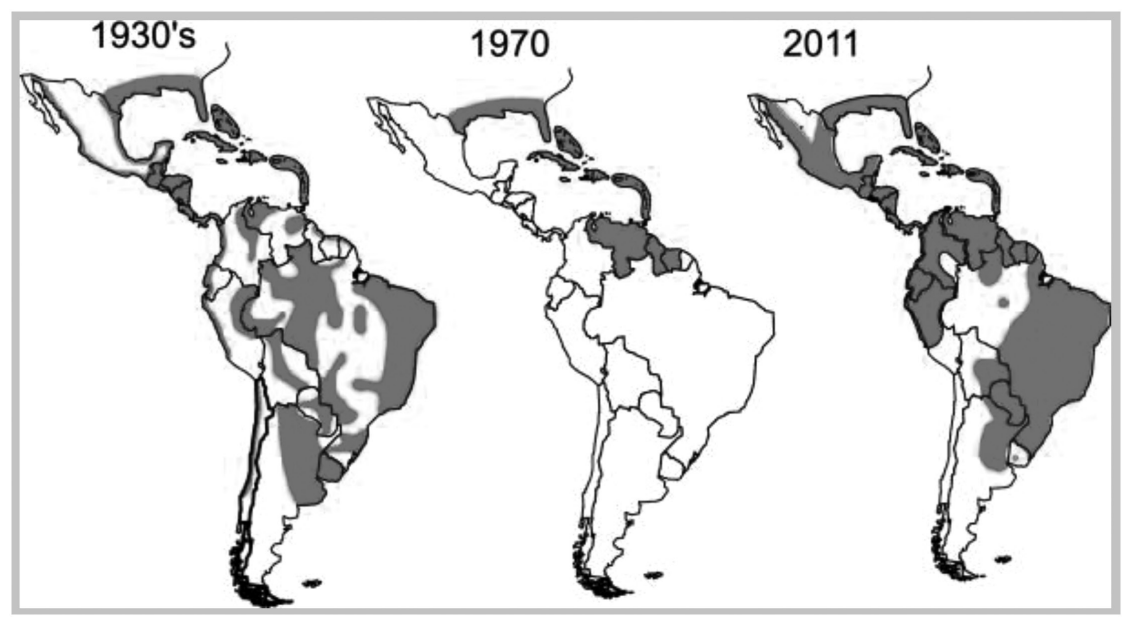

FIGURE 6.2 Map of Aedes aegypti distribution in South and Central America in the 1930s, 1970 and 2011. Creative Commons [from Gubler, D.J. 2011. "Dengue, Urbanization and Globalization: The Unholy Trinity of the 21st Century." Tropical Medicine and Health, 39(4) Suppl:3-11. doi: 10.2149/tmh.2011-S05]. 
Soper knew much more about the behaviour of Aedes aegypti, but as was so often the case in eradication campaigns, assumptions about universal ecology meant setbacks when confronting ecological complexity. A case in point was the discovery that in the Caribbean, Aedes aegypti could breed high up in tree holes, rendering ineffective spraying regimes that assumed this mosquito only bred near human habitations. The question about the possible ill effects of complete removal of a species from its habitat does not seem to have even been raised.

Nor were ethical questions raised in Soper's eradication projects about the risks of Paris Green and then DDT to humans, animals and the environment more generally. There was no mention about seeking consent to inspect people's homes or spray them with powerful chemicals; instead, mandatory inspections were often imposed on households, with fines for non-compliance. Soper maintained that eradication worked best under authoritarian governments: "if you have democracy, you cannot have eradication," was his view. It was a "command from the top" model that reflected his experience in Brazil under the authoritarian President of the 1930s, Getúlio Vargas. It was not a model that translated well into more democratic settings, where consultation, community participation and citizens' consent are necessary for success. Furthermore, a single disease focus, with its separate and unique organizational structure, also had limits, since integrating the needs of other public health activities was difficult.

Finally, the over-reliance on a biomedical model of public health meant that there was a strong bias against or neglect of social methods of controlling disease, such as installing piped water, screened windows and ensuring regular rubbish collection as ways to ward off mosquito-borne diseases. It is well known that improved housing and socio-economic conditions were and are factors in the secular declines of diseases, but investments to overcome social and economic inequality were by and large absent from post-war campaigns to control and eradicate mosquitoes.

\section{Control versus eradication}

So we end with the same question we started with: Could we/should we eradicate mosquitoes?

It seems to me that something has to be done to keep in check the mosquitoes that transmit dangerous human diseases. But what and how? Sending 220,000 soldiers to Brazilian neighbourhoods to deal with Zika was more an exercise in public relations than a thought-out project of public health. Community vector control is judged to be generally unsuccessful as well, so how can our strategies be reconfigured? Why has anti-mosquito work been neglected in Brazil, even though dengue epidemics were, even before Zika, a recurring problem? Why has it been so hard to remodel public health around vector control using appropriate ecological, biological and social methods?

New tools, such as releasing Wolbachia-infected mosquitoes to control dengue, are being tried out as demonstration experiments (Dorigatti et al., 
2018). I doubt that they will escape the "could we/should we" entanglements. What are the effects of releasing bio-engineered mosquitoes on the ecological balance? Are their risks understood? How will members of the public be put in a position to evaluate them? Would some "old tech" methods be better?

I ask these questions in light of the fact that arboviruses represent some of today's most important global health threats, products of intensive human migration, urbanization, globalization, climate change, inadequate vaccination, and failures of former vector control efforts. Aedes aegypti is now found worldwide (Gubler, 2011; Ferguson, 2018). Annually, there are 200,000 detected cases of yellow fever and 30,000 deaths, figures WHO regards as underestimates by a factor of 10 to 250 (Tomori, 2004). Africa is the chief worry; after independence, vaccination rates in countries at risk fell off sharply. In 1986-1992, despite the importation of 20 million doses of yellow fever vaccine, Nigeria was unable to control an epidemic. In 2017, WHO announced a new yellow fever initiative, "Eliminate Yellow Fever Epidemics" (EYE) in response to further urban outbreaks in Africa, with the goal of restoring depleted stockpiles of the vaccine over a ten-year period (Brès, 1971; Garske et al., 2014). We must ask, therefore, was Soper right? Is vaccination going to be available and enough, absent other methods of disease mitigation, including improvements in sanitation and urban infrastructure? And what about Zika, and dengue-one with no vaccine, the other with a vaccine of very partial efficacy, and neither with treatment other than palliative care?

Soper always considered "species eradication" his most original contribution to public health. Later, all four of his efforts were judged to be failures, or at best limited in relevance to health policies, in methods and outcomes. As a result, Soper's reputation suffered a dramatic decline after his death. But before we write off Soper as a discredited figure in public health, might we look again, to reassess his work in the light of present-day post-Zika concerns? There is, of course, no going back to the Soper era: new ways to control mosquitoes must be found to suit our own day's political, ecological and scientific circumstances. But could certain "Soperian moments" suggest ways for reimagining some methods of dealing with mosquitoes, short of the utopian dream of complete eradication?

The downsides of Soper's approach are obvious: a chemical and polluting model; a reliance on a universal one-size-fits-all ecology; disregard for social needs such as housing and sanitation; the lack of community participation; little ongoing research; use of military rather than cooperative metaphors; and so on. And meanwhile, post Soper (he died more than 40 years ago), cities like Recife in Brazil, where Zika first erupted, are far larger, more chaotic, more unequal and more trash-filled than ever before. Controlling Aedes aegypti is much more difficult than before.

But we must also acknowledge Soper's positive contributions. These would include efficiency in surveillance and tenacity in anti-mosquito efforts; enormous attention to detail; inspections of the inspectors; adequate funding and political commitment (Downs, 1968). Above all, Soper continued his work even in the 
absence of mosquitoes and/or cases of yellow fever. Such ongoing methods and preventive attitude are rare and are very different from an epidemic-generated, reactive and generally ineffective resort to mosquito reduction (Ooi et al., 2006).

The lesson of history is that revised methods of mosquito control are needed in the short-to-intermediate term (Ferguson et al., 2016, Ferguson 2018). We also need to keep in mind that, originally, the anti-mosquito yellow fever vector programmes aimed not at complete eradication, but at reducing the targeted mosquito indices to a low level, below which the transmission of the pathogen was found not to be sustainable. In the case of yellow fever, reducing the incidence of Aedes aegypti mosquito larvae to a presence in 5\% or less of houses in a targeted population stopped yellow fever transmission for decades throughout the Americas.

The goal of mosquito reduction, tailored to epidemiological circumstances, along with much more participatory models of public health than in the past, seems to me to combine the positive aspects of Soper's determination to deal with the mosquito as a major factor in disease transmission, with René Dubos's ecological view that takes into account the dynamic and continuous processes by which insects, pathogens and humans interact, adapt and co-evolve (Litsios, 1997). This view achieves a better balance between human health and environmental health as we adjust our policies to confront climate change, which may well spread mosquito-borne infections and accelerate the loss of species.

Controlling mosquitoes raises difficult ethical and ecological questions; but aiming for the reduction of specific mosquito populations, by new means, including social ones, is possible, and less distorting of public health than aiming for vector eradication.

\section{Note}

1 Sections of this chapter are drawn from my book on eradication (Stepan, 2011).

\section{Bibliography}

Benchimol, J. 2001. Febre Amarela: A Doença e a Vacina: Uma História Inacaba. Rio de Janeiro: Editora Fiocruz.

Brès, P. 1971. Recent Epidemics of Yellow Fever in Africa. Symposium on Vector Control and the Recrudescence of Vector-Borne Disease. Washington: PAHO and WHO.

Chippaux, Jean-Philippe, and Alain Chippaux. 2018. Yellow Fever in Africa and the Americas: A Historical and Epidemiological Perspective. Journal of Venomous Animals and Toxins Including Tropical Diseases, 24(1): 1-14. doi:10.4269/ajtmh.1969.18.341

Dorigatti, Ilaria et al. 2018. Using Wolbachia for Dengue Control: Insights from Modelling. Trends in Parasitology, 34(2): 102-113. doi:10.1016/j.pt.2017.11.002

Downs, Wilbur G. 1968. The Story of Yellow Fever Since Walter Reed. Bulletin of the New York Academy of Medicine, 44(6): 721-727.

Durieux, C. 1956. Mass Yellow Fever Vaccination in French Africa South of the Sahara. WHO Monograph Series No. 30, Yellow Fever Vaccination. Geneva: WHO, 115-122. 
Ferguson, Neil M. 2018. Challenges and Opportunities in Controlling Mosquito-Borne Infections. Nature, 559: 490-497. https://doi.org/10.1038/s41586-018-0318-5

Ferguson, Neil M. et al. 2016. Countering the Zika Epidemic in Latin America. Science, 353(6297): 353-354. doi:10.1126/science.aag0219

Frierson, Gordon. 2010. The Yellow Fever Vaccine: A History. Yale Journal of Biology and Medicine, 83: 77-85.

Garske, T. et al. 2014. Yellow Fever in Africa: Estimating the Burden of Disease and Impact of Mass Vaccination from Outbreak and Serological Data. PLOS Medicine, 11(5): e1001638. doi:10.1371/journal.pmed.1001638

Gubler, D.J. 2004. The Changing Epidemiology of Yellow Fever and Dengue, 19002003: Full Circle. Comparative Immunology, Microbiology \& Infectious Diseases, 27: 319-330.

Gubler, D.J. 2011. Dengue, Urbanization and Globalization: The Unholy Trinity of the 21st Century. Tropical Medicine and Health, 39(4): 3-11. doi:10.2149/tmh.2011-S05

Hall, Marcus. 2010. Environmental Imperialism in Sardinia: Pesticides and Politics in the Struggle against Malaria. In Marco Armiero and Marcus Hall, eds. Nature and History in Modern Italy. Athens: Ohio University Press, 70-86.

Litsios, Socrates. 1997. René J. Dubos and Fred L. Soper: Their Contrasting Views of Vector and Disease Eradication. Perspectives in Biology and Medicine, 41(1): 138-149.

Lowe, Rachel et al. 2018. The Zika Virus Epidemic in Brazil: From Discovery to Future Implications. International Journal of Environmental Research and Public Health, 15(1). doi:10.3390/ijerph15010096

Löwy, Ilana. 1997. Epidemiology, Immunology, and Yellow Fever: The Rockefeller Foundation in Brazil, 1923-1939. Journal of the History of Biology, 30: 397-417.

Monath, Thomas P. 1991. Yellow Fever: Victor, Victoria? Conqueror, Conquest? Epidemics and Research in the Last 40 Years \& Prospects for the Future. American Journal of Tropical Medicine, 45(1): 1-43.

Ooi, E.E., Kee-Tai Goh, and Duane J. Gubler. 2006. Dengue Prevention and 35 Years of Dengue Control in Singapore. Emerging Infectious Diseases, 12(6): 887-893.

Packard, R.M., and P. Gadelha. 1997. A Land Filled with Mosquitoes: Fred L. Soper, the Rockefeller Foundation, and the Anopheles Gambiae Invasion of Brazil. Medical Anthropology, 17(3): 215-238.

Peltier, Maurice. 1947. Yellow Fever Vaccination Simple or Associated with Vaccination against Smallpox of the Population of French West Africa by the Method of the Pasteur Institute of Dakar. American Journal of Public Health, 37(8): 1026-1032.

Sencer, David J. 1969. Health Protection in a Shrinking World. American Journal of Tropical Medicine \& Hygiene, 18(3): 341-345. doi:10.4269/ajtmh.1969.18.341

Soper, F.L. 1963. The Elimination of Urban Yellow Fever in the Americas through the Eradication of Aedes Aegypti. American Journal of Public Health 53(1): 7-16.

Soper, F. L., and D.B. Wilson. 1942. Species Eradication: A Practical Goal of Species Reduction in the Control of Mosquito-Borne Disease. Journal of the National Malaria Society, 1: 5-24.

Stepan, Nancy Leys. 2011. Eradication: Ridding the World of Diseases for Ever? London: Reaktion Books.

Strode, G.K. 1951. Yellow Fever. New York: McGraw-Hill.

Tomori, Oyewale. 2004. Yellow Fever: The Returning Plague. Critical Reviews in Clinical Laboratory Sciences, 41(4): 391-427. 